\title{
Analytical Treatment of Aviation Events \\ with State Aircraft of the Russian Federation Due to Avionics Failures from 2000 till 2017
}

Ivan M. Ivanov, Dmitry S. Viktorov and Viktor N. Bondarev* Military Academy of Aero-Space Defense named after the Marshal of Soviet Union G.K. Zhukov 50 Zhigareva Str., Tver, 170022, Russia

This paper studies aviation accidents and aviation incidents with state aircraft of the Russian Federation due to avionics failures from 2000 till 2017 and also considers main causes of their initiation.

Keywords: aviation accidents, aviation incidents, avionics failures.

\section{Анализ авиационных событий \\ с государственными воздушными судами РФ \\ из-за отказов бортового радиоэлектронного оборудования \\ за период 2000-2017 гг.}

\author{
И.М. Иванов, Д.С. Викторов, В.Н. Бондарев \\ Военная академия воздушно-космической оборонь \\ им. Маршала Советского Союза Г.К. Жукова \\ Россия, 170022, Тверь, ул. Жигарева, 50
}

В статье проводится анализ авиачионных происшествий и авиачионных инцидентов $c$ государственными воздушными судами РФ из-за отказов бортового радиоэлектронного

(C) Siberian Federal University. All rights reserved

This work is licensed under a Creative Commons Attribution-NonCommercial 4.0 International License (CC BY-NC 4.0).

* Corresponding author E-mail address: boxter2004@mail.ru, viktorov.dmitry@yandex.ru 
оборудования за период с 2000 по 2017 год и рассматриваются основные причины их возникновения.

Ключевые слова: авиационные происшествия, авиационные инциденты, отказы бортового радиоэлектронного оборудования.

Развитие бортового радиоэлектронного оборудования (БРЭО) характеризуется постоянным увеличением числа решаемых задач, повышением сложности алгоритмов обработки информации, расширением адаптивных и интеллектуальных возможностей, поиском новых архитектурных решений по построению комплексов бортового оборудования (КБО) и снижению массогабаритных характеристик при одновременном сохранении высоких показателей надежности и отказоустойчивости.

Отказы авиационной техники (АТ) негативно влияют на обеспечение качественного, своевременного и должного выполнения задач по предназначению в условиях интенсификации летной деятельности авиационных частей воздушно-космических сил (ВКС).

К числу возможных причин возникновения отказов АТ относят конструктивнопроизводственные недостатки (КПН), которые могут быть вызваны дефектами проектирования и производства.

Для выявления степени критичности данной причины предлагается проанализировать состояние аварийности в авиации ВКС.

Таким образом, целью статьи является анализ влияния КПН БРЭО воздушных судов (ВС), вызванных дефектами проектирования и производства, на обеспечение качественного, своевременного и должного выполнения задач по предназначению.

Анализ основан на информации, представленной в [1-7], и охватывает период с 2000 по 1-е полугодие 2017 г., что позволяет рассмотреть авиационные события (АС) с ВС различных принципов построения КБО.

Согласно [8], в зависимости от степени тяжести АС классифицируются таким образом:

- авиационные происшествия (АП);

- чрезвычайные и наземные происшествия (ЧП) и (НП);

- авиационные инциденты (АИ).

За указанный период в государственной авиации РФ выявлено 28449 АИ, из них 4739 серьезных авиационных инцидентов (САИ) и 177 серьезных авиационных инцидентов с повреждением воздушного судна (САИП); 160 АП, из них 73 катастрофы (К) и 87 аварий (А); 39 ЧП и НП, из них 36 ЧП и 3 НП.

По группам факторов (причин) Ф(П) [8] АС с ВС распределились следующим образом:

- первая группа Ф(П) (нарушения (упущения) личного состава при организации, производстве, управлении и обеспечении полетов) - 98 АП (50 катастроф и 48 аварий), 11521 АИ (120 САИП и 1182 САИ), 30 ЧП и НП (27 ЧП и 3 НП);

- вторая группа Ф(П) (отказы авиационной техники, не связанные с действиями личного состава, участвующего в производстве полетов) - 58 АП (22 катастрофы и 36 аварий), 15687 АИ (43 САИП и 3225 САИ), 5 ЧП;

- третья группа Ф(П) (другие причины) - 4 АП (4 аварии), 1241 АИ (14 САИП и 332 САИ), 4 ЧП. 
Диаграмма, представленная на рис. 1, характеризует процентное распределение АC по группам (факторам) причин.

Из анализа диаграммы следует, что доля авиационных событий из-за отказов АТ, не связанных с действиями личного состава, участвующего в организации и производстве полетов (2-я $\Phi(П))$, наиболее значительна и составляет 55 \% от общего количества АС, произошедших с 2000 г. по 1-е полугодие 2017 г.

Разделим вторую группу Ф(П) на отказы, связанные с планером и двигателем ВС (двигатели, элементы силовой установки, шасси, гидравлическая система, фонарь, окна, крыло, тормозная и посадочная парашютная система и т.д.), и отказы БРЭО, состоящее из: авиационного оборудования (бортовые средства контроля и регистрации полетных данных, приборы контроля двигателя, пилотажно-навигационное оборудование, система управления самолетом и др.), радиоэлектронного оборудования (связное оборудование, радиоаппаратура самолетовождения) и авиационного вооружения (прицельно-вычислительные комплексы и устройства, система управления оружием).

Соотношение количества АС за анализируемый период времени, обусловленных отказами планера и двигателей ВС и БРЭО, показано на рис. 2.

Представленные данные свидетельствуют о том, что 41 \% АС из-за отказов АТ с государственными ВС РФ вызваны отказами БРЭО.

По подгруппам данные АС распределились следующим образом:

- КПН - 5658 АС (8 катастроф, 9 аварий, 1 ЧП, 3 САИП, 488 САИ и 5151 АИ);

- отказы, причины которых не установлены, но могут быть наиболее вероятными (ОПНУ) - 552 АС (32 САИ, 520 АИ);

- недостатки ремонта (НР) - 169 АС (19 САИ, 150 АИ) (рис. 3).

Видно, что в большинстве случаев АС были обусловлены отказами БРЭО вследствие КПН (89\%).

На рис. 4 представлено процентное распределение АС по причине КПН БРЭО.

Таким образом, по причине КПН отказов БРЭО выявлено 8 катастроф, 9 аварий, 1 чрезвычайное происшествие, 3 серьезных авиационных инцидента с повреждением ави-

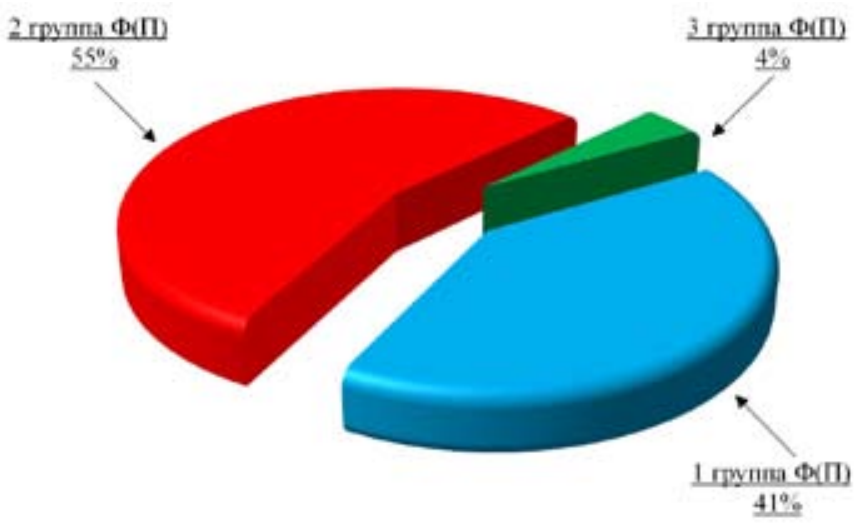

Рис. 1. Диаграмма распределения АС по группам факторов (причин)

Fig. 1. Diagram of aviation events distribution according to groups of factors (causes) 


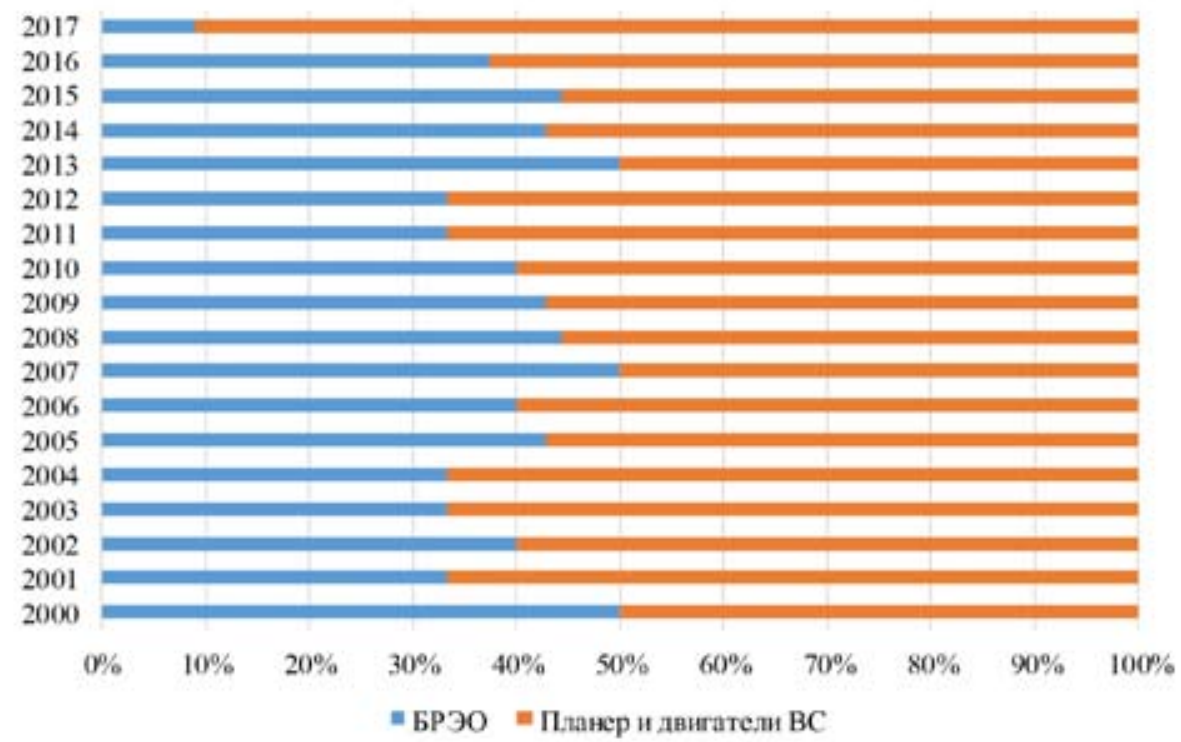

Рис. 2. Гистограмма соотношения отказов планера и двигателей $\mathrm{BC}$ к отказам БРЭО за исследуемый период

Fig. 2. Histogram of aircraft airframe and engines failures to avionics failures within the period under study

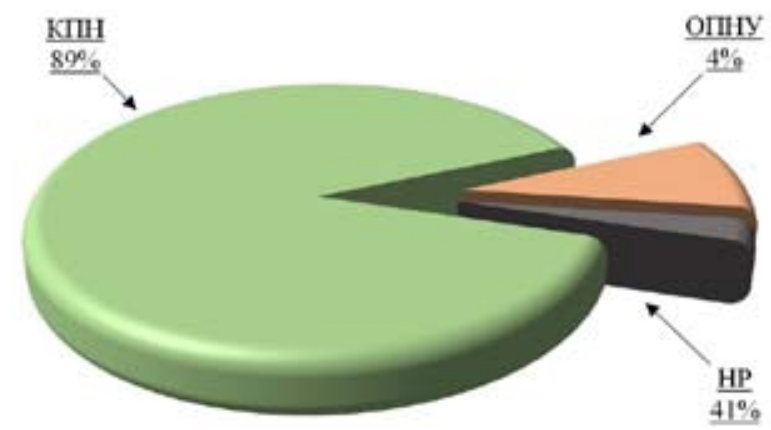

Рис. 3. Диаграмма распределения Ф(П) 2-й группы из-за отказов БРЭО по подгруппам

Fig. 3. Diagram of factors (causes) distribution of the second group due to avionics failures into subgroups

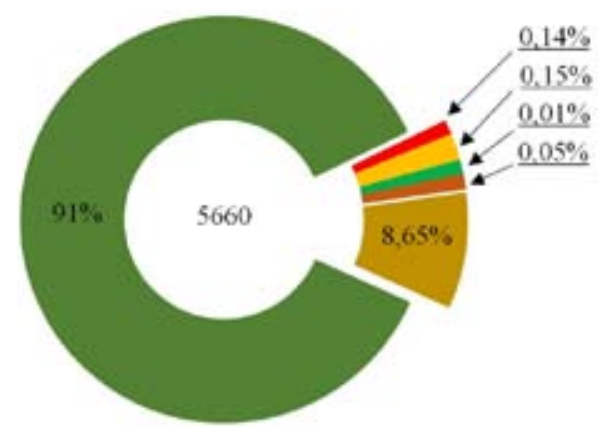

- Катастрофа - 8

Еварин - 9

"Чрезвычайнос происшсстиие - I

ЕСАИП - 3

=САИ -488

ЕИ. 5151

Рис. 4. Процентное распределение АС по причине КПН БРЭО

Fig. 4. Percentage distribution of aviation events because of avionics design-manufacturing troubles 
ационной техники, 488 серьезных авиационных инцидентов и 5151 авиационный инцидент.

Так, 24.07.2003 произошла катастрофа вертолета Ми-8, вероятной причиной которой является отказ системы управления. По причине возникновения ошибки в счислении координат бортовой системой навигации, приведшей к выходу из разворота с отклонением по широте на 5 км, 12.11.2003 потерпел катастрофу МиГ-29. В связи с возникшим отказом блока защиты и управления БЗУ-6ВМ, входящим в состав блока регулировки, защиты и управления генератора постоянного тока БРЗУ-4в, 8.07.2004 потерпел катастрофу дальний сверхзвуковой ракетоносец-бомбардировщик Ту-22м3. По программе первого испытательного полета после ремонта, 29.07.2008 истребитель Су-27уб потерпел катастрофу, обусловленную отказом продольного канала системы дистанционного управления СДУ-10У. 2.11.2010 при выполнении полетов возникла особая ситуация, в результате которой произошла катастрофа, обусловленная неинформативным отказом правого авиагоризонта и, как следствие, неправильная работа автопилота АП-З4Б (неадекватная, с отработкой ошибочных сигналов) по каналу крена и тангажа в полете, что привело к перекладке автомата перекоса на величину полного хода раздвижки автопилота по обоим каналам и при наличии сильного бокового ветра слева стало причиной сваливания в правый крен и пикирование. Ночью 28.12.2010 потерпел катастрофу Ан-22 изза отказа системы управления, выразившегося в нарушении работоспособности механизма автотриммирования, что привело к резкому отклонению рулей направления до значения $14^{\circ}$, развитию глубокого скольжения с превышением критического угла скольжения, энергичному кренению с переходом самолета на снижение по спиральной траектории. При выполнении планового полета 6.09.2012 в связи с неинформативным отказом канала индикации крена командного пилотажного прибора, выразившимся в индикации околонулевых показаний крена, произошла катастрофа МиГ-29. После выполнения задания в зоне при выходе на аэродром 15.04.2014 потерпел крушение Як-130 из-за отказа системы управления самолетом, наиболее вероятно обусловленного повреждением электрических связей в коммутационной печатной плате А2 контейнера К-60 КСУ-130.

В результате аварий было утрачено: Су-27п 3 ед., Су-27уб, Су-27см, Су-24м, Су-24мр, МиГ25рб, Як-130. 17.05.2001 по причине многочисленных отказов его систем и непрекращающегося (после сброса фонаря) задымления кабины был утрачен Су-27п. 26.03.2002 произошла авария истребителя Су-27п из-за отказа основной и резервной системы дистанционного управления. Причиной аварии самолета МиГ-25рб 2.07.2003 явилась потеря скорости вследствие выключения летчиком правого двигателя, обусловленного отказом в системе информации о работоспособности двигателей. При выполнении полета по плану боевой подготовки 12.02.2004 г. произошла авария самолета Су-24м, причиной которой явился отказ управления в системе изменения стреловидности крыла. При перелете в составе группы 15.09.2015 произошла авария самолета Су-27п в связи с потерей летчиком ориентировки при выполнении полетного задания, обусловленной отказом навигационного оборудования, что привело к полной выработке топлива на самолете и самовыключению двигателей в воздухе. Перед выполнением захода на посадку 19.06.2009, экипаж фронтового бомбардировщика Су-24м приступил к перестановке крыла из положения $45^{\circ}$ в положение $16^{\circ}$. Крыло в положение $16^{\circ}$ не установилось. Произошел отказ генераторов переменного тока, навигационных приборов, повлекший за собой необходи-

$$
-779-
$$


мость выхода экипажа в зону аварийного покидания самолета. В 2010 г. произошло две аварии. Так, 29.05.2010 упал самолет Як-130. Причиной аварии самолета явилось нарушение работоспособности комплексной системы управления КСУ-130, выразившееся в формировании и выдаче на привода рулевых поверхностей несоответствующих режиму полета управляющих сигналов в продольном и боковых каналах, что привело к неуправляемому и непарируемому движению самолета, его выходу на закритические углы атаки, сваливанию и штопору. 20.09.2010 при выполнении самолетом облета после ремонта произошла авария Су-27уб. Причиной аварии явилось нарушение работоспособности системы дистанционного управления СДУ10У, выразившееся в формировании и выдаче на приводы рулевых поверхностей демпферами тангажа и курса управляющих сигналов, не соответствующих режиму полета, что привело к продольной раскачке и сваливанию самолета.

При выполнении боевой задачи 11.11.2002 произошло чрезвычайное происшествие, в результате которого был утрачен вертолет Ми-24п по причине отказа системы управления вертолета.

При расследовании САИП, произошедшего 5.09.2001 с самолетом Ту-160, был выявлен конструктивный недостаток, выразившийся в отказе блока БУ-66 системы управления интерцепторами. На вертолете Ми-8мтв-2 при заходе на посадку 3.08.2002 произошел САИП по причине отказа системы автоматического регулирования левого двигателя. Недостатки в разработке алгоритма программного обеспечения БЦВМ, выразившиеся во временной задержке в цепях вооружения при выборе типа вооружения кнопкой «тип Оружия», обусловили САИП вертолета Ми-28н 19.06.2009.

Основными причинами возникновения САИ/АИ за исследуемый период явились отказы блоков, относящихся к различным системам ВС: системе электроснабжения, пилотажнонавигационному оборудованию, системе управления самолетом, противопожарному оборудованию, оборудованию автоматического управления полетом, радиоаппаратуре самолетовождения, связному оборудованию, прицельно-вычислительным комплексам и устройствам и т.д.

Так, например, в 2012 г. было зарегистрировано два САИ с самолетом Су-35С, выразившиеся в кратковременном сбое связи между процессором «А» вычислителей управления ВУ35-135-01 и контроллерами вычислителей приводов ВП-35-1 и ВП-35-3 и аппаратном отказе БЦВМ-1 с сохранением частичного обмена по МКИО, что не позволило передать управление МКИО к БЦВМ-2. При определении причин возникновения САИ с самолетом Су-34 были выявлены: отказ системы электроснабжения постоянного тока, причина которого не установлена, но наиболее вероятной может быть отказ БРЗУ27В или ГСБК18П; отсутствие резерва бокового канала в результате отказа датчика ДАД системы СДУ-10.

Наиболее часто встречаются следующие отказы:

- отказы исполнительных блоков автоматики систем пожарной сигнализации, пожаротушения и предупреждения о пожаре самолетов МиГ-29, МиГ-31, Су-24, Су-25, Су-27 и Ил-76, вертолетов Ми-8;

- отказы систем электронной автоматики самолетов МиГ-29, Ту-22м3 и Ту-134;

- отказы электрических и электронных систем и устройств управления силовыми установками самолетов Су-24, Су-25, Су-27, МиГ-29, МиГ-31, Ту-22м3, Ту-134, Ту-160, вер- 
толетов Ми-8, Ми-24 и Ми-26. Все они сопровождались отказами одного из двигателей либо ложной сигнализацией об отказе двигателя с последующим его выключением экипажем.

Согласно [1], большинство САИ произошло в процессе боевой подготовки летной деятельности. В меньшей степени авиационные инциденты были выявлены при выполнении воздушных перевозок, специальных заданий и проведений летно-тактических учений.

Таким образом, проведенный анализ авиационных событий с государственными ВС РФ за исследуемый период позволяет сделать следующие выводы:

1. 41 \% авиационных событий, относящихся ко 2-й группе Ф(П), обусловлены отказами бортового радиоэлектронного оборудования, по причине которых произошло 8 катастроф, 9 аварий, 1 чрезвычайное происшествие, 3 серьезных авиационных инцидента с повреждением воздушного судна, 488 серьезных авиационных инцидентов и 5151 авиационный инцидент.

2. Основными опасными факторами, приводящими к снижению надежности авиационной техники, являются:

- физическое старение образцов АТ, состоящих на вооружении в государственной авиации Российской Федерации;

- низкая надежность элементной базы бортового оборудования воздушных судов (в том числе новых и модернизированных);

- недостаточное финансирование работ по устранению опасных конструктивнопроизводственных недостатков, определяемых комиссиями по результатам расследования АП;

- проявления конструктивных недостатков, допущенных при создании новой авиатехники.

В качестве рекомендаций по снижению отказов бортового радиоэлектронного оборудования предлагается применение версионной избыточности на начальных стадиях разработки, которая позволит парировать дефекты проектирования и производства и в результате снизить количество авиационных событий по $2 \Phi(П)$.

\section{Список литературы}

[1] Ежемесячные экспресс-бюллетени по аварийности в государственной авиации Российской Федерации. М. : МО РФ СБП авиации ВС РФ, 2000 - 2017. [Monthly express newsletters on accidents in the state aviation of the Russian Federation. Moscow. Ministry of Defense of the Russian Federation, Aviation Safety Service, 2000-2017 (in Russian)].

[2] Информационный выпуск по авиационным происшествиям и авиационным инцидентам за первое полугодие 2014 года. М. : МО РФ ВВС, 2014. 125 c. [Information release on aviation accidents and incidents for the first half of 2014. Moscow. Ministry of Defense of the Russian Federation, Air Force, 2014, 125 p. (in Russian)].

[3] Информационный выпуск по авиационным происшествиям и авиационным инцидентам за второе полугодие 2014 года. М. : МО РФ ВВС, 2014. 143 c. [Information release on aviation accidents and incidents for the second half of 2014. Moscow. Ministry of Defense of the Russian Federation, Air Force, 2014, 143 p. (in Russian)]. 
[4] Информационный выпуск по авиационным происшествиям и авиационным инцидентам за первое полугодие 2015 года. М. : МО РФ ВВС, 2015. 128 c. [Information release on aviation accidents and incidents for the first half of 2015. Moscow. Ministry of Defense of the Russian Federation, Air Force, 2015, 128 p. (in Russian)].

[5] Информационный выпуск по авиационным происшествиям и авиационным инцидентам за второе полугодие 2015 года. М. : МО РФ ВВС, 2015. 191 c. [Information release on aviation accidents and incidents for the second half of 2015. Moscow. Ministry of Defense of the Russian Federation, Air Force, 2014, 191 p. (in Russian)].

[6] Информационный выпуск по авиационным происшествиям и авиационным инцидентам за первое полугодие 2016 года. М. : МО РФ ВВС, 2016. 83 c. [Information release on aviation accidents and incidents for the first half of 2016. Moscow. Ministry of Defense of the Russian Federation, Air Force, 2016, 83 p. (in Russian)].

[7] Информационный выпуск по авиационным происшествиям и авиационным инцидентам за второе полугодие 2016 года. М. : МО РФ ВВС, 2016. 218 c. [Information release on aviation accidents and incidents for the second half of 2016. Moscow. Ministry of Defense of the Russian Federation, Air Force, 2014, 218 p. (in Russian)].

[8] Правила расследования авиационных происшествий и авиационных инцидентов с государственными воздушными судами в Российской Федерации : [утв. постановлением правительства РФ № Пр.-1329 от 2 дек. 2014 г.]. М. : МО РФ, 2016. 88 c. [Rules of investigation of aviation accidents and aviation incidents with state aircraft in the Russian Federation.: approved resolution of the government of the Russian Federation order No. 1329 of December 2, 2014. Moscow. Ministry of Defense of the Russian Federation, 2016. 88 p. (in Russian)] 